\title{
Study on Flame Stabilization in a Dual-Mode Combustor Using Optical Measurements
}

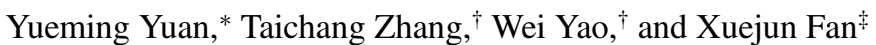 \\ State Key Laboratory of High Temperature Gas Dynamics, Chinese Academy of Sciences, 100190 \\ Beijing, People's Republic of China
}

DOI: $10.2514 / 1 . B 35689$

\begin{abstract}
Flame stabilization in a dual-mode scramjet combustor was studied using simultaneous detection of flowfield and reaction zone. The instantaneous reactive flowfield was clearly visualized using an improved pulsed schlieren system, whereas the reaction zone was marked by $\mathrm{CH}^{*}$ chemiluminescence. Experiments were performed in a Mach 2.5 model combustor with the total temperature of $1275 \pm 25 \mathrm{~K}$ and the total pressure of $1.0 \mathrm{MPa}$. Ethylene was used as fuel with equivalence ratios varied from 0.258 to 0.411 . Four typical flame stabilized locations and corresponding flowfields are presented. When no choke occurs, the flame is stabilized in the cavity or the shear layer. Schlieren images show that the flow in the reaction zone of the latter case is supersonic. When the combustor is choked at the injection location, the flame oscillates between the shear layer and the jet wake, and the flow in the reaction zone becomes subsonic. When the flame is stabilized in the jet wake, autoignition can occur due to the compression of precombustion shock train. The short-lived aerodynamic throat formed near the injection location may be the possible cause for triggering the unsteady flame oscillation. The effects of heat release on flame stabilization modes are discussed.
\end{abstract}

\section{Nomenclature}

$\begin{array}{ll}M a & =\text { Mach number } \\ P & =\text { pressure, } \mathrm{MPa} \\ T & =\text { temperature, } \mathrm{K} \\ t & =\text { time, } \mathrm{s} \\ \varphi & =\text { equivalence ratio }\end{array}$

Subscript

$0=$ stagnant condition

Superscript

$* \quad=\quad$ excited electronic state of the radical

\section{Introduction}

$\mathbf{T}$ HE flame stabilization in combustors with cavity has been extensively studied. The cavity as a flameholder has been widely used due to a low total pressure loss in dual-mode combustors, which potentially operate in a wide range of flight Mach numbers $[1,2]$. Choi et al. [3] found that the cavity played the role of flameholder in a broad range of flow speeds by simulating the detailed flowfield in a dual-mode scramjet combustor. Yang et al. $[4,5]$ reported that ignition characteristics and flame stabilization can be improved through the increase of flow characteristic time and the decrease of reaction characteristic time, namely decreasing the flow velocity and increasing the temperature and pressure in the combustor section. The recirculation zone in the cavity provides a long residence time for fuel/air mixing and combustion. The cavity flame offers a source of heat and radicals to ignite and stabilize the flame in

Received 7 December 2014; revision received 26 April 2015; accepted for publication 29 May 2015; published online 10 August 2015. Copyright (C) 2015 by the American Institute of Aeronautics and Astronautics, Inc. All rights reserved. Copies of this paper may be made for personal or internal use, on condition that the copier pay the $\$ 10.00$ per-copy fee to the Copyright Clearance Center, Inc., 222 Rosewood Drive, Danvers, MA 01923; include the code 1533-3876/15 and \$10.00 in correspondence with the CCC.

*Assistant Professor, Institute of Mechanics, No. 15 Beisihuanxi Road. Member AIAA.

${ }^{\dagger}$ Associate Professor, Institute of Mechanics, No. 15 Beisihuanxi Road. Member AIAA.

†Professor, Institute of Mechanics, No. 15 Beisihuanxi Road; xfan@imech .ac.cn. Member AIAA (Corresponding Author). the main flow [6]. Micka and Driscoll [7] found two distinct flame stabilization locations in the ramjet mode: one anchored in the cavity shear layer at low stagnation temperature, and the other stabilized in the fuel jet wake at high stagnation temperature. In the intermediate range of stagnation temperatures, the reaction zone oscillates between the jet wake and the cavity stabilization locations. Fotia and Driscoll [8] thought the flame speed drove the oscillatory behavior of the flame in the unstable regime. Flame is only stabilized in the shear layer in the scramjet mode [9]. Sun et al. [10] confirmed a triple-flame model by large-eddy simulation for the flame stabilization using cavity. At very high flight Mach number, the temperature of incoming flow is high enough for autoignition to occur, such as Ben-Yakar [11] found that autoignition occurred when the hydrogen or ethylene was injected into supersonic crossflow with a total temperature as high as $4000 \mathrm{~K}$. In such cases, the combustion stabilization problem reduces to a mixing problem [12].

Because the flame stabilization in the dual-mode ramjet/scramjet combustor is essentially determined by the interaction between flow dynamics and chemical reactions, the simultaneous detection of flowfield and reaction zone would benefit the further understanding of the stabilization mechanism. In this paper, simultaneous detection of flowfield and reaction zone was performed by synchronizing the schlieren system and $\mathrm{CH}^{*}$ chemiluminescence photography. In addition, the average Mach-number profiles of the flowfield are computed using a quasi-one-dimensional scramjet performance model [13]. Based on those results, the flame stabilization in a dual-mode scramjet combustor is discussed.

\section{Experimental Specifications}

\section{A. Test Facility}

All experiments in the present work were conducted in a $M a=2.5$ direct-connect wind tunnel, which consists of a vitiated air supply system, multipurpose supersonic model combustor [14-16], and simultaneous pulsed schlieren and $\mathrm{CH}^{*}$ chemiluminescence system. The vitiated air, which is supplied by burning hydrogen in air with oxygen replenishment, has a stagnation temperature of 700-2200 K and a stagnation pressure of $0.6-4.5 \mathrm{MPa}$. Figure 1 shows the model combustor with a total length of $1600 \mathrm{~mm}$, which is composed of four sections (i.e., a 350-mm-long constant-area section with a cross section of $51 \mathrm{~mm}$ in height and $70 \mathrm{~mm}$ in width, a 500-mm-long divergent section with a $1.3 \mathrm{deg}$ expansion angle, a 400 -mm-long divergent section with $2.9 \mathrm{deg}$, and a 350-mm-long divergent section with $4.0 \mathrm{deg}$ ). An interchangeable integrated fuel-injection/flameholder cavity module is installed on one side of the combustor. The cavity 
has the depth of $12 \mathrm{~mm}$, a $45 \mathrm{deg}$ aft ramp angle, and an overall length to depth ratio of 4 . The ethylene is injected through a 4-mm-diam orifice, which is located $56 \mathrm{~mm}$ upstream of the cavity leading edge. Additionally, two 2.5-mm-diam orifices are used for pilot hydrogen injection, which are located $8 \mathrm{~mm}$ upstream of the cavity leading edge. Both ethylene and pilot hydrogen are transversely injected into the airflow. For optical access and observation, a pair of quartz windows facing the cavity module is installed on both sides of the combustor, as shown in Fig. 1.

The stagnation pressure and temperature of the vitiated air were respectively measured using a CYB-10S pressure transducer (accuracy $\pm 0.1 \%$, produced by Beijing ZhongHangJiDian Technology Co. Ltd.) and a Type-B thermocouple. The distribution of static pressure in the axial direction was measured through a number of pressure taps distributed along the test section. Each tap was instrumented with a Motorola MPX2200 pressure transducer within an uncertainty of $0.1 \%$.

\section{B. Simultaneous Pulsed Schlieren and $\mathrm{CH}^{*}$ Chemiluminescence Photography}

Flow visualization is critical for understanding the combustion process in a dual-mode combustor. Schlieren photography has been widely employed to study the interactions between combustion and flowfield [17-28], which include the transient flow behaviors during thermal choking process $[17,18]$ and the flow features of flame holding $[9,19-23]$. However, the clear images, showing instantaneous structures of supersonic combustion flowfield, are actually scarce.

Capturing clear schlieren images on supersonic combustion flowfield should resolve two key problems: 1) eliminating the interference from combustion radiation, and 2) freezing the high-speed flowfield. A pulsed schlieren system, improved in this paper by using a powerful nanosecond flashlamp, can suppress the background radiation effectively in an exposure time of microseconds, whereas the short flash duration of nanoseconds can freeze the high-speed flow. In addition, to observe the interaction between the combustion and the flow at each transient time, the schlieren and chemiluminescence systems are used in combination through simultaneously controlling.

To learn more details about reactive flowfield, a pulsed schlieren system was improved by the authors' group [29]. The schematic diagram of the optical measurement system is shown in Fig. 2. The light source of pulsed schlieren system is a Nanolite nanosecond flashlamp (KL-L), which has a repetition rate up to $20 \mathrm{kHz}$, short pulse duration of $18 \mathrm{~ns}$, and a high flash energy up to $25 \mathrm{MJ}$ for each pulse. Schlieren images are captured by a high-speed complementary metal-oxidesemiconductor (CMOS) camera system PCO.1200hs, which has a shortest exposure time of $1 \mu \mathrm{s}$ and a maximum frame rate of 31,250 frames per second. A 9514-type pulse generator (Quantum Composers, Inc.) is used to synchronize the flashlamp with the camera.

The flashlamp is a narrow-band incoherent pulsed source, which can avoid the diffraction and coherent artifact noise appearing when

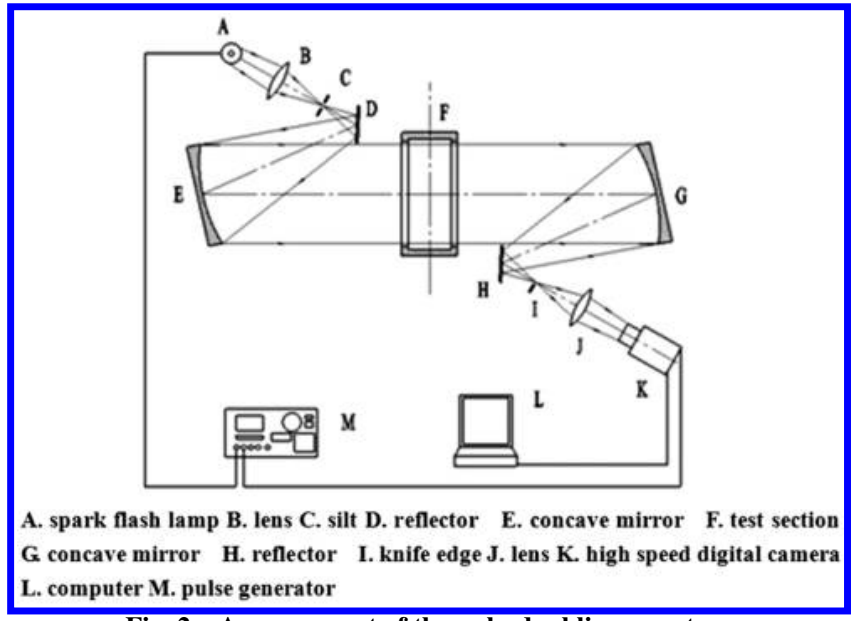

Fig. 2 Arrangement of the pulsed schlieren system.

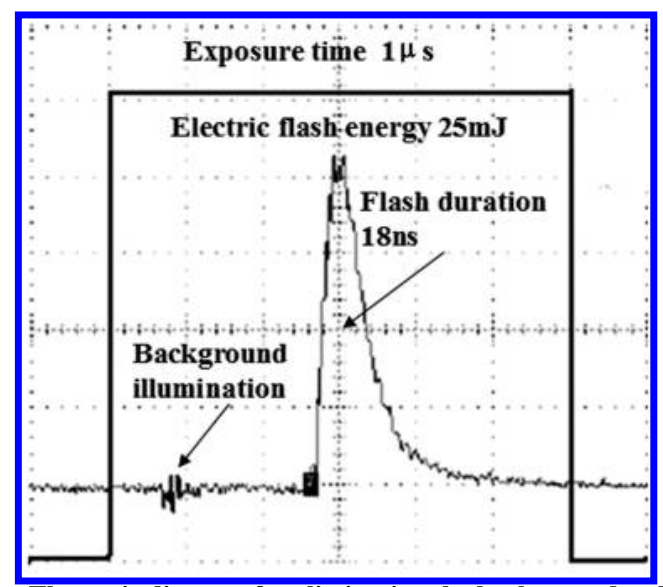

Fig. 3 Theoretic diagram for eliminating the background radiation.

using laser source [30-32]. As depicted in Fig. 3, within an exposure time scale of microseconds, the luminous density of the flash spark is several orders of the magnitude higher than the combustion radiation; thus, the interference from combustion radiation can be easily filtered.

During the short flash duration, the high-speed flowfield can be considered temporally frozen, and the instantaneous flowfield structures can be precisely captured by the pulsed schlieren system. In the test section, the maximum flow speed is less than $1200 \mathrm{~m} / \mathrm{s}$ at the entrance Mach number of 2.5, and thus the maximum flow traveling distance in a flash duration is $21.6 \mu \mathrm{m}$. Furthermore, because the demagnification of the pulsed schlieren system is approximately 0.1 , the flow traveling distance projected on the CMOS array is also approximately $2.16 \mu \mathrm{m}$, which is even shorter than a pixel scale.

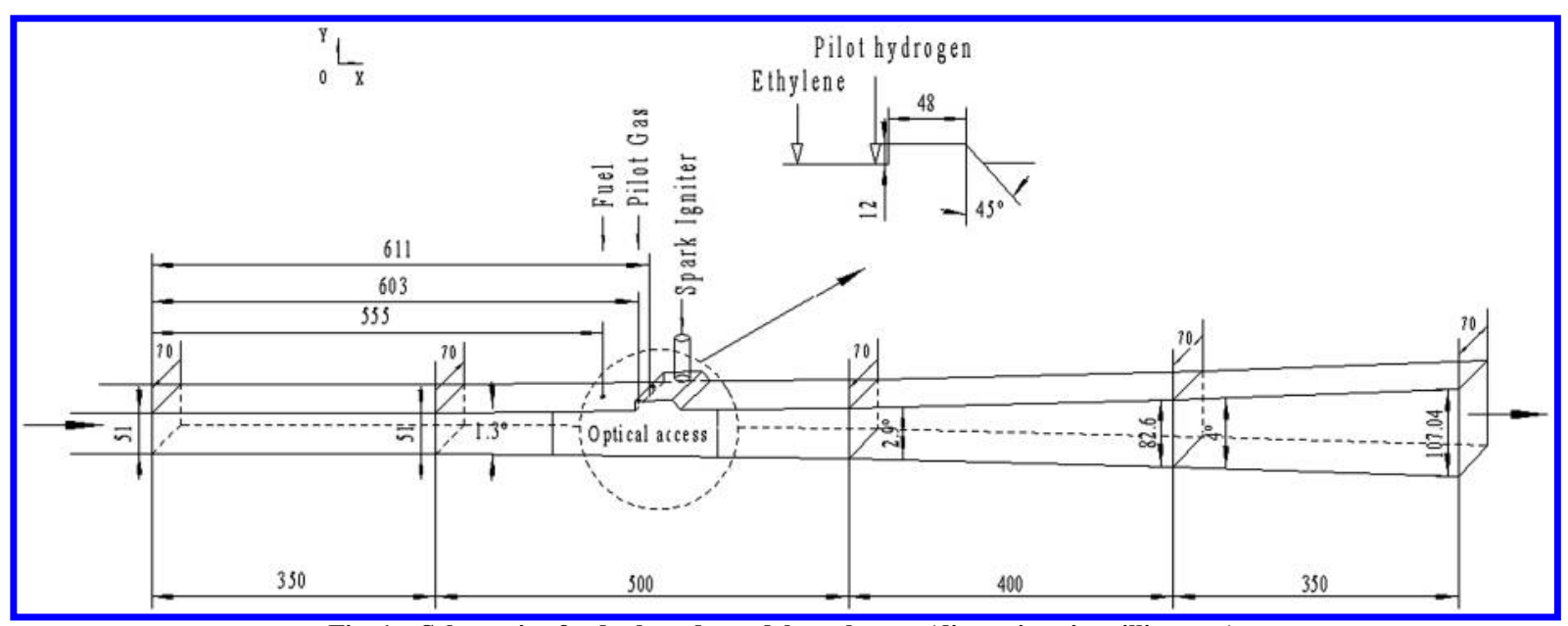

Fig. 1 Schematic of a dual-mode model combustor (dimensions in millimeters). 
$\mathrm{CH}$ radical is an intermediate species with a nanosecond lifetime and exists only in the fuel consumption layer; therefore, direct $\mathrm{CH}^{*}$ chemiluminescence can be used to image the primary reaction zone [33-35]. In this paper, $\mathrm{CH}^{*}$ chemiluminescence was recorded synchronously with pulsed schlieren using high-speed camera v711 (phantom) with a CH band-filter MF434-17 and an exposure time of $100 \mu$ s. Although $\mathrm{CH}^{*}$ chemiluminescence is a line-of-sight and time-averaged measurement, it provides some in-depth information for qualitatively analyzing the interaction between flowfiled and chemical reaction.

\section{Results and Discussions}

\section{A. Visualization of Reactive Flowfield}

The performance of pulsed schlieren system is tested through comparing the visualized results between reactive and nonreactive flowfields. The parameters of air flow are the same for the two cases (e.g., the stagnation temperature is $1274 \mathrm{~K}$, and the stagnation pressure is 1.0 MPa). Ethylene is used as the fuel with an equivalence ratio of $\varphi=0.258$. The only difference is that the spark igniter is not activated in the nonreactive case.

Figure 4 shows the stagnation pressure curves of pilot hydrogen, ethylene, and vitiated air for the two aforementioned cases. A steady $M a=2.5$ airflow was established at approximately $3.0 \mathrm{~s}$ and lasted about $3.5 \mathrm{~s}$. Pilot hydrogen was injected at $3.5 \mathrm{~s}$ and shut off completely at $5.5 \mathrm{~s}$. Ethylene was injected at $4.1 \mathrm{~s}$ and shut off at $6.4 \mathrm{~s}$. Thus, the stable combustion of ethylene lasts from 5.5 to $6.4 \mathrm{~s}$.

Direct $\mathrm{CH}^{*}$ chemiluminescence was synchronized with schlieren to mark the reaction zone. The exposure time of schlieren was set to $1 \mu \mathrm{s}$, and the frame rate was $200 \mathrm{~Hz}$. The exposure time of direct $\mathrm{CH}^{*}$ chemiluminescence was set to $100 \mu \mathrm{s}$.

Figure 5 shows the simultaneous flowfield structures and flame structure for the reactive and nonreactive flows, respectively. In the reactive flowfield, direct $\mathrm{CH}^{*}$ chemiluminescence indicates that reaction zone resides in the cavity. It can be seen that no background radiation due to combustion appears in this region compared with the schlieren image of the nonreactive flowfield. Detailed flowfield structures can be clearly captured both in the reactive and nonreactive flowfield schlieren images, such as Mach barrel, separation shock, bow shock, oblique shock, reflected shock, shear layer, as well as large-scale structures. It notes that the symmetric oblique shock waves, upstream of the bow shock, are produced due to the uneven flange between the isolator and combustor. However, the structure of the shear layer is lost, as shown in Fig. 5a. The shear layer blocked by a black region can be attributed to the fact that the light passing through this region deflects a large angle due to large density and the deflected rays are completely cut off by the knife edge. However when the direction of knife edge is adjusted to the opposite, a detailed shear-layer structure can be obtained as shown in Fig. 6, which on the contrary lost the other detailed flow structures (e.g., shock and jet

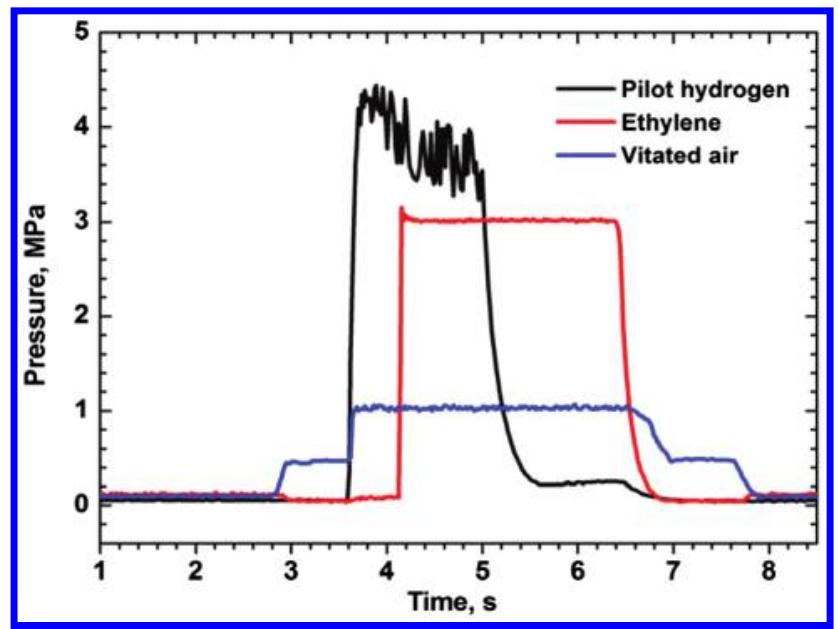

Fig. 4 Time histories of pilot hydrogen pressure, ethylene pressure, and stagnation pressure of vitiated air.

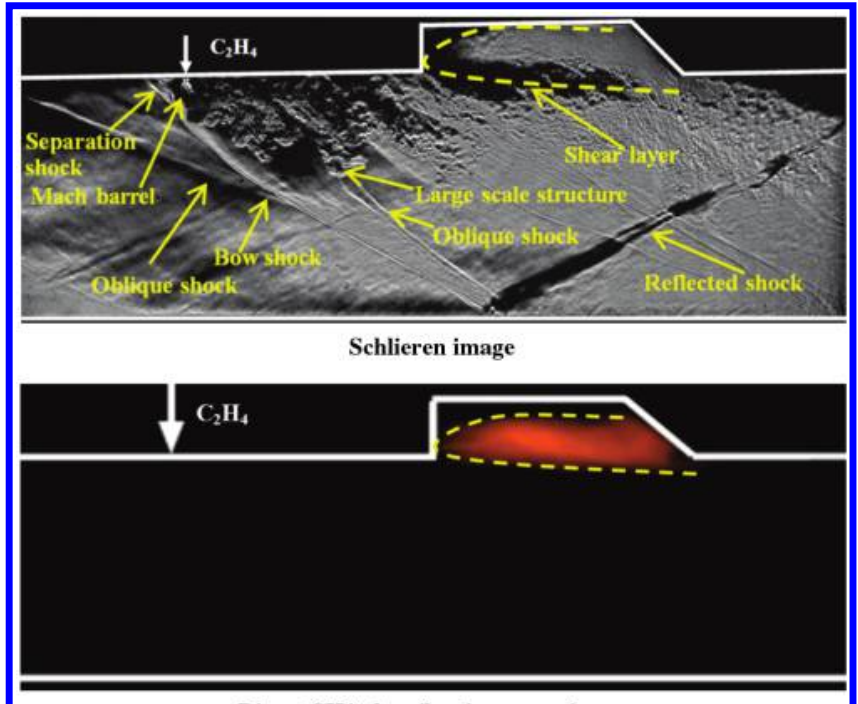

Direct $\mathrm{CH}^{*}$ chemiluminescence image

a) Reactive flowfield
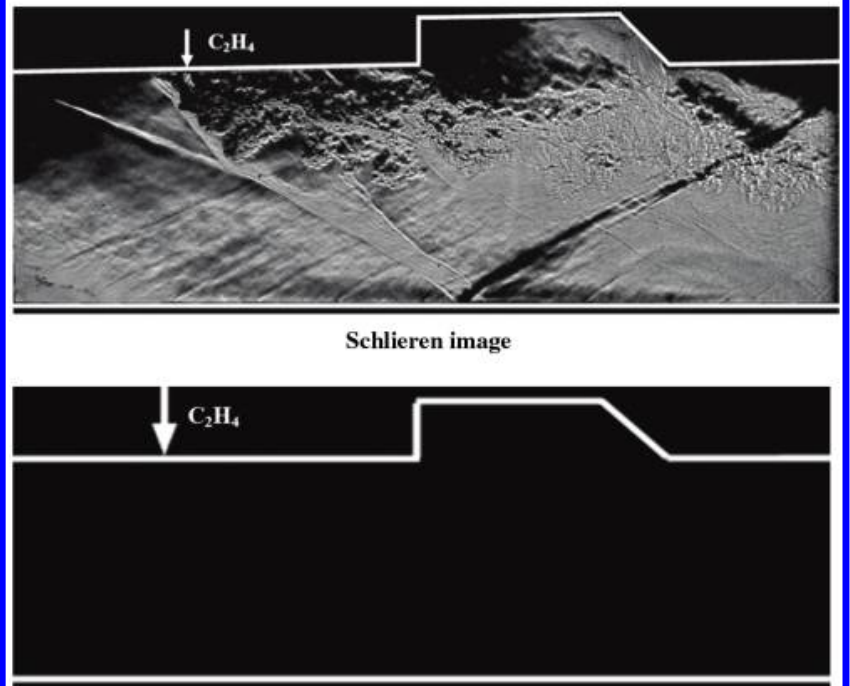

Direct $\mathrm{CH}^{*}$ chemiluminescence imag

b) Nonreactive flowfield

Fig. 5 Simultaneous flowfield structure and flame structure for reactive and nonreactive flow at $\varphi=0.258$ (dashed line is used to mark the boundary of reaction zone).

structures) that used to be clear in Fig. 5a. To analyze the shock/flame interaction, clear shock and jet structures are retained at the cost of losing the shear-layer structure. As shown in Fig. 5a, the reaction zone was distinctly marked with a dashed line in the schlieren image for the convenience of further analysis on the interaction between reaction and flowfield.

\section{B. Flame Stabilization Modes}

Five typical cases, from A to E, were selected to investigate the flame stabilization as shown in Table $\underline{1}$. The equivalence ratios,

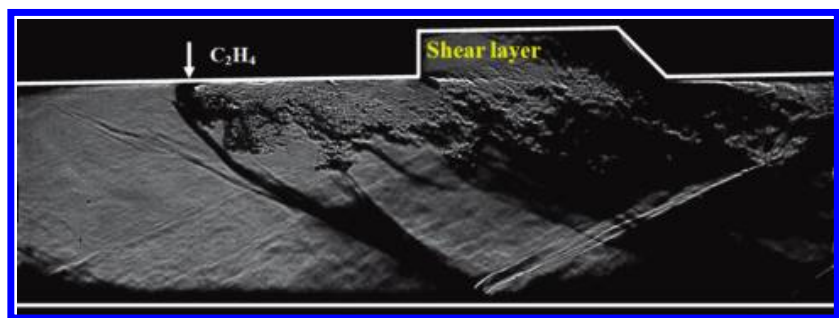

Fig. 6 Schlieren image of reactive flowfield with the opposite direction of knife edge. 
Table 1 Experimental conditions

\begin{tabular}{lccccccc}
\hline \hline Figure & Case & Flame location & $T_{0}, \mathrm{~K}$ & $P_{0}, \mathrm{MPa}$ & $\boldsymbol{\varphi}$ & $\begin{array}{c}\text { Average Mach number } \\
\text { at injection point }\end{array}$ & $\begin{array}{c}\text { Thermal choking } \\
\text { condition }\end{array}$ \\
\hline $\mathbf{5}$ & $\mathrm{A}$ & Inside the cavity & 1274 & 1.0 & 0.258 & $>1$ & No \\
$\overline{9}$ & $\mathrm{~B}$ & Shear layer & 1292 & 1.0 & 0.291 & $>1$ & No \\
$\overline{10}$ & $\mathrm{C}$ & Shear layer & 1278 & 1.0 & 0.326 & $>1$ & Yes \\
$\overline{11}$ & $\mathrm{D}$ & oscillation & 1257 & 1.0 & 0.376 & $=1$ & Yes \\
$\underline{\underline{12}}$ & $\mathrm{E}$ & Jet wake & 1278 & 1.0 & 0.411 & $<1$ & Yes \\
\hline \hline
\end{tabular}

defined as the ratio of total flow rates between the ethylene and air coming flow, are controlled from 0.258 to 0.411 through varying the stagnation fuel pressure upstream the sonic nozzle. The stagnation temperature $T_{0}$ was $1275 \pm 25 \mathrm{~K}$, and the stagnation pressure $P_{0}$ was almost 1.0 MPa. The Mach number at the entrance of isolator was fixed at 2.5.

With the increase of equivalence ratio, four modes of flame stabilization location were observed (i.e., inside the cavity, in the cavity shear layer, oscillating between the shear layer and the fuel jet wake, and in the fuel jet wake). The static pressure in the combustor also rises with the increase of fuel equivalence ratio as shown in Fig. 7. Based on the static pressure, the average Mach-number distribution for each case was calculated by a one-dimensional (1-D) analysis method [13]. Although the 1-D model cannot characterize a three-dimensional flowfield, the calculated results approximate the average values for qualitative analysis of the flowfield. The pressure fluctuations observed in the tests can be as large as $\pm 3 \%$ for quasisteady periods due to the complex interactions among the wave structures, combustion, and boundary layer in the near-wall regions. The fluctuations of calculated Mach number also drop in the range of $\pm 3 \%$ corresponding to the pressure fluctuations. According to the Mach-number profiles, the average flow speeds at the fuel-injection location were supersonic in cases A, B, and C, whereas subsonic in case $\mathrm{E}$ and exactly choked there in case $\mathrm{D}$. The combustor has a subsonic region around the injector in cases $\mathrm{C}, \mathrm{D}$, and $\mathrm{E}$ with a thermal throat downstream of the cavity.

\section{Flame Stabilized Inside the Cavity}

For case A with $\varphi=0.258, \mathrm{CH}$ radicals concentrate inside the cavity with no $\mathrm{CH}^{*}$ chemiluminescence appearing outside the cavity, which indicates that the flame only resides inside the cavity. The Mach-number profile in Fig. 8 shows that the flowfield remains supersonic throughout the combustor with an average Mach number above 2.0 .

Thus, a low fuel plume penetration with poor fuel/air mixing is resulted due to the high momentum flux of airflow. Under this condition, the cavity, downstream the injector, provides a long residence time for fuel/air mixing and a continuous source of high-temperature radicals for chemical reaction established in the shortest distance possible. Large-scale vortices oscillating and propagating downstream along the jet-airflow interface preenhance ethylene/air mixing

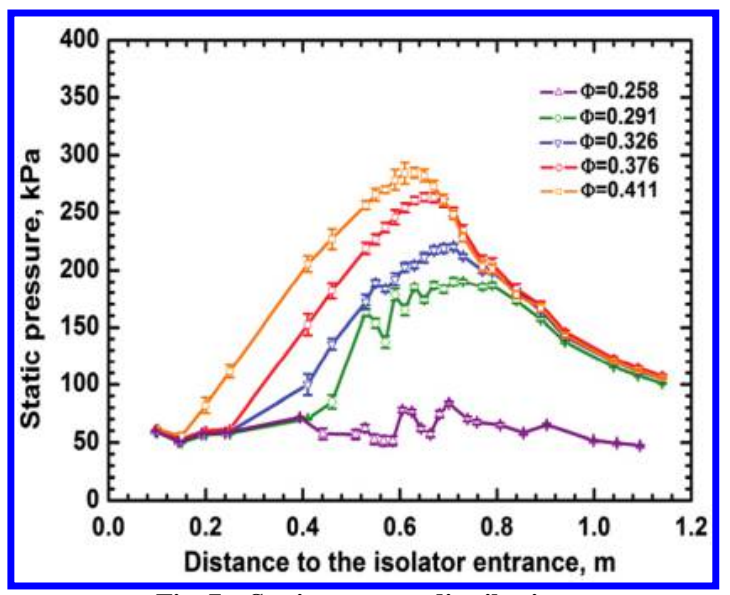

Fig. 7 Static pressure distribution. upstream of the cavity. The mixtures are then transported into the recirculation to facilitate the combustion mode.

\section{Flame Stabilized in the Shear Layer}

For case B with $\varphi=0.291$, more heat release from combustion increases the static pressure as shown in Fig. 7. Thus, shocks in the combustor are enhanced; for example, in Fig. $\overline{9}$, two normal shocks are formed to match the backpressure. The flow speed, through these normal shocks, is decreased to $M a=1.0$ around the leading edge of cavity, as indicated in Fig. 8. More fuel distributes above the cavity due to the jet penetration increase and facilitates the fuel/air mixing based on the reduction in flow speed. More heat release, transferred to the main flow, heats the cavity shear layer to a suitable temperature, which can initiate the combustion. In addition, the hot radicals in the recirculation also keep heating the adjacent shear layer. As a result, the flame is stabilized in the shear layer.

In case $\mathrm{C}$ with a further increased equivalence ratio of $\boldsymbol{\varphi}=0.326$, thermal choking apparently occurred in the combustor, and a subsonic region appeared downstream the injector, as indicated by Fig. 8 . Although the flame is still stabilized in the shear layer, $\mathrm{CH}$ radicals can be found in the fuel jet wake over the cavity, which is not observed for case B. Thermal choking brings a considerable increase in static pressure in both the combustor and the isolator, as shown in Fig. 7. A precombustion shock train, with the tails of shock train appearing in the field of view as shown in Fig. 10, has been created to match the increasing backpressure. The downstream anchor point of the shock train is located around the leading edge of cavity, which agrees well with the location of maximum pressure recovery as illustrated in Fig. 7. The flow speed is decreased to about $M a=1.0$ before the fuel injector and reduced to subsonic around the leading edge of cavity, as indicated in Fig. 8. Because of the rising of momentum flux ratio, the jet penetration is increased and fuel/air mixing is enhanced in the jet wake. Shock train reduces the flow velocity and raises the static temperature in the jet wake, which respectively increases the flow residence time and reduces the ignition delay time. As a result, it is possible that an autoignition occurs in the jet wake where $\mathrm{CH}^{*}$ chemiluminescence appears. The combustion in the adjacent shear layer also offers heat sources to ignite the mixture and stabilize the combustion in the jet wake. The role of autoignition in the reaction in the jet wake is worth further analysis.

In both cases B and C, the flame is mainly stabilized in the shear layer, and the Mach numbers at the isolator exit are larger than 1,

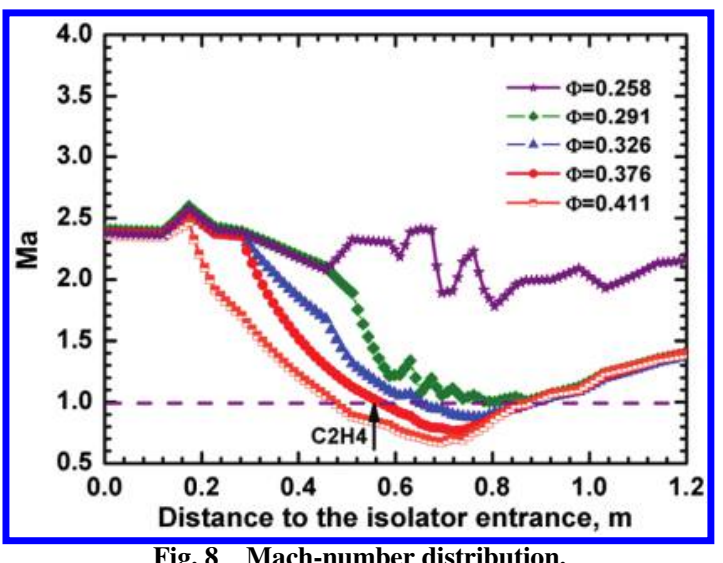




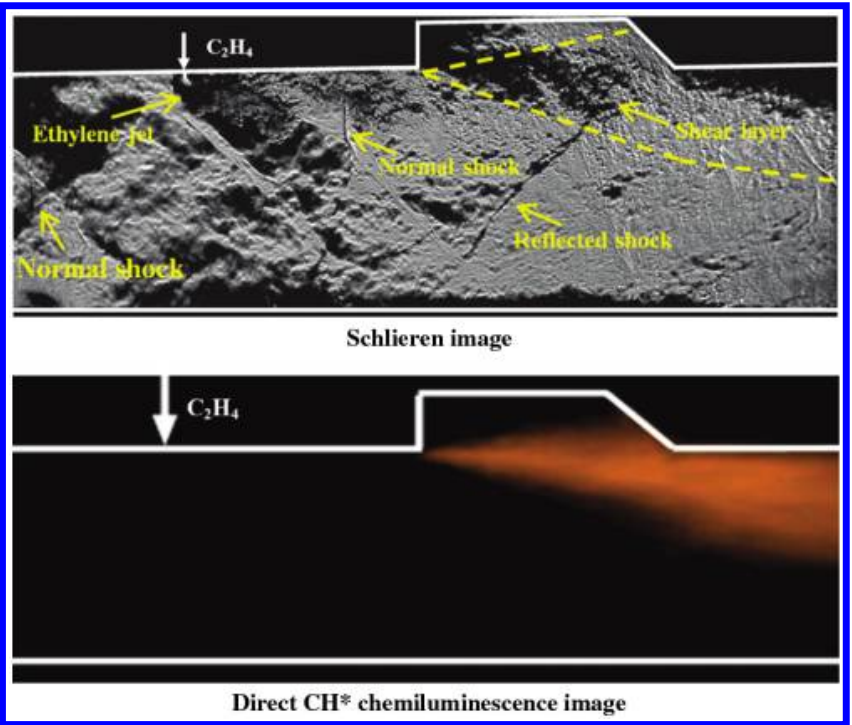

Fig. 9 Schlieren and simultaneous direct $\mathrm{CH}^{*}$ chemiluminescence images for the ethylene combustion at $\varphi=0.291$.

implying that the combustor is run in scramjet operation mode. In other studies $[7,9,12]$, flame stabilized in the shear layer is also observed under ramjet operation mode with a low stagnation temperature. Thus, it can be concluded that there is no direct correspondence between the flame stabilization mode and the combustor operation mode.

\section{Flame Oscillation Between the Shear Layer and the Fuel Jet Wake}

Different flame stabilization locations oscillate along with different flowfield structures in one test of case D at $\varphi=0.376$, as denoted by the sequential images in Fig. 11. Figure 11a shows that a bow shock appears upstream the injector, and precombustion shock train exists downstream the injector at $t=5.635 \mathrm{~s}$, indicating that the flowfield near the injector is supersonic. The fuel plume penetration is less than half the height of the combustor. $\mathrm{CH}^{*}$ chemiluminescence shows that the reaction zone is stabilized in the shear layer. Figure $11 \mathrm{~b}$ shows a distinctly different phenomenon occurring at $t=5.64 \mathrm{~s}$. The shock train is nearly pushed out from the schlieren view field with a left oblique shock formed near the injector. Comparing with the flowfield shown in Fig. 11a, the fuel jet penetrates to the opposite wall, with the flow downstream the oblique shock reduced to subsonic completely. $\mathrm{CH}^{*}$ chemiluminescence covers most of the ethylene jet

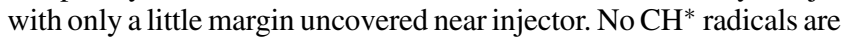

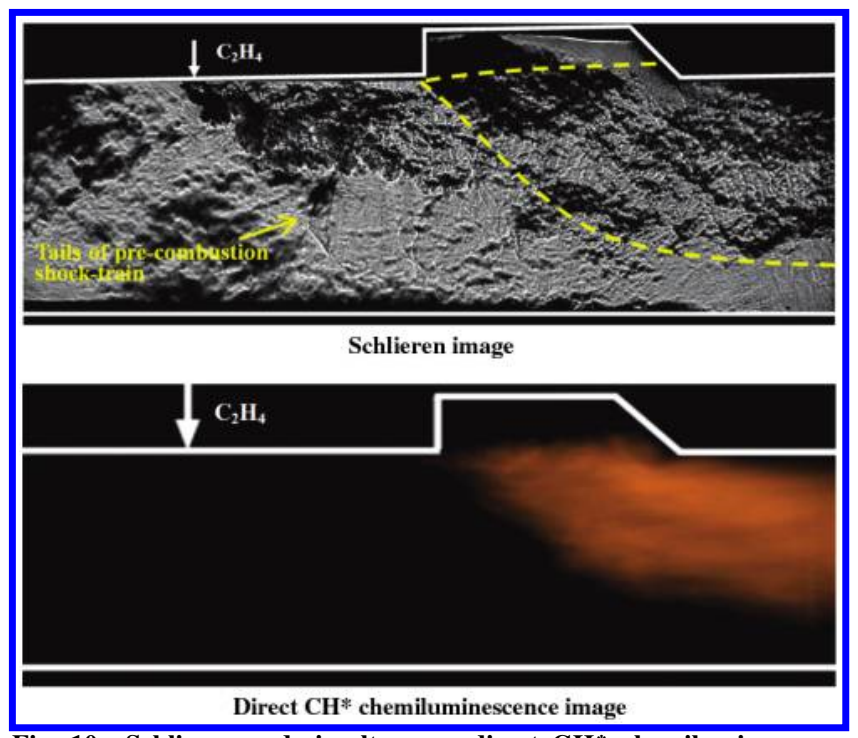

Fig. 10 Schlieren and simultaneous direct $\mathrm{CH}^{*}$ chemiluminescence images for the ethylene combustion at $\varphi=\mathbf{0 . 3 2 6}$. present inside the cavity and in the shear layer, suggesting that an autoignition occurs in the jet wake. Figure $11 \mathrm{c}$ shows that the precombustion shock train moves downstream, and the reaction zone also propagates back to the vicinity of cavity at $t=5.645 \mathrm{~s}$, accompanied by a reduction in fuel plume penetration. The reaction zone at $t=5.650 \mathrm{~s}$ is located at a mediate point between two flame stabilized locations. The downstream anchor point of the shock train is just located near the injector, where the flow speed should be close to Mach 1.0 due to a weak oblique shock existing there. Downstream the shock train, the flowfield is subsonic, and the reaction zone resides in the jet wake over again, and the flow structures are similar to those described for Fig. 11b.

The underlying mechanism for the oscillation is possibly related with the reciprocating movement of aerodynamics throat, whose formation near the injection point is contributed by the heat addition from the fuel combustion. As the combustion process, the increase in backpressure, due to heat addition, enhances the shock train and pushes them upstream toward the isolator. The shock train induces a reduction in crossflow speed and an increase in static temperature at the location of injector, facilitating the autoignition occurring in the jet wake and motivating the reaction zone propagating upstream toward the injector. The fuel plume penetrates further into the crossflow with a large region of momentum deficit, which again induces a proportional decrease in flow speed. When the crossflow is decelerated to subsonic, a dynamic throat will form at the location where the Mach number is 1.0. As indicated in Fig. 8, the dynamic throat is just located at the injection point, where the static temperature and flow speed are very sensitive to the depth of penetration. Further increase in jet penetration is possible to reaccelerate the flow to the supersonic accompanied with the decrease in static pressure and temperature. As a result, the reaction zone is difficult to be anchored in the jet wake because the flow residence time is shortened. Finally, the main reaction zone propagates back to the shear layer. The whole process can be analogized to the flow coming into a supersonic diffuser. Thus, the possible mechanisms can be inferred that an aerodynamic throat forming near the injection location, due to the fuel combustion, induces the oscillation between the two flame stabilization modes. However, evolvement of the dynamic throat and the flame oscillation needs to be further verified by high-speed simultaneous capturing of schlieren and $\mathrm{CH}^{*}$ chemiluminescence combined with static pressure measurement at a frequency high enough to time-resolve the dynamic process.

Micka and Driscoll [7] also found flame oscillation between two flame stabilization modes under ramjet mode operation. It cannot analyze the phenomenon using the previously proposed reason due to the lack of flowfield information in their work. More experiments in wide conditions need be performed in further study.

\section{Flame Stabilized in the Jet Wake}

For case E with $\varphi=0.411$, the pressure increases so significantly in both the combustor and the isolator that the shock train has been pushed upstream to the isolator. The high jet penetration, by the higher momentum flux ratio, provides a better near-field mixing. The long flow residence time and high static temperature, downstream the shock train, offer a suitable environment for autoignition. Under this condition, the injected ethylene is ignited almost immediately after the injector, and the reaction zone was observed stabilized in the jet wake as shown in Fig. 12

\section{Effects of Heat Release on the Flame Stabilization Mode}

The flame stabilization mode is significantly affected by the heat release, which rises with the increase of fuel equivalence ratio from 0.256 to 0.411 . For case $\mathrm{A}$, the equivalence ratio is too low to produce enough heat from combustion to rise flow temperature in shear layer. Thus, fuel/air mixture can only combust in the cavity recirculation. As elevating the equivalence ratio to 0.291 , the heat release from the cavity increases the temperature of the shear layer to a suitable value, which can initiate the fuel/air combustion in shear layer. The hot products are transited into the cavity recirculation and keep heating the adjacent shear layer. Consequently, the flame can be stabilized in 


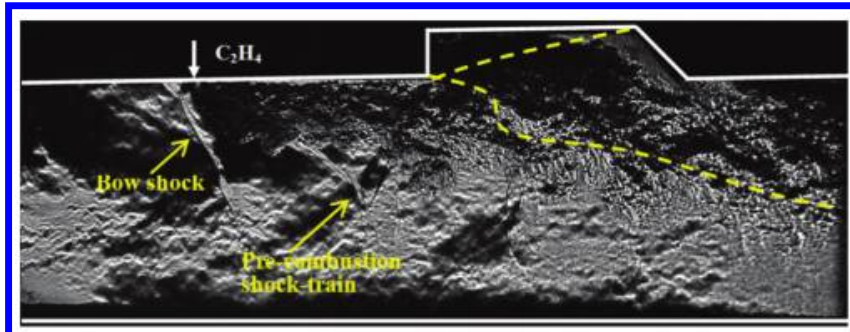

Schlieren image

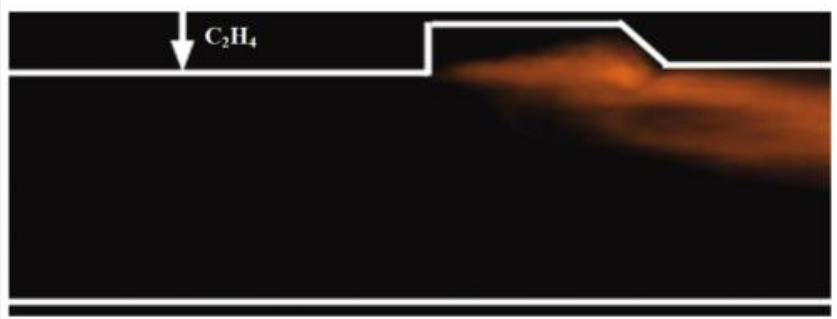

Direct $\mathrm{CH}^{*}$ chemiluminescence image

a) $t=\mathbf{5 . 6 3 5} \mathrm{s}$

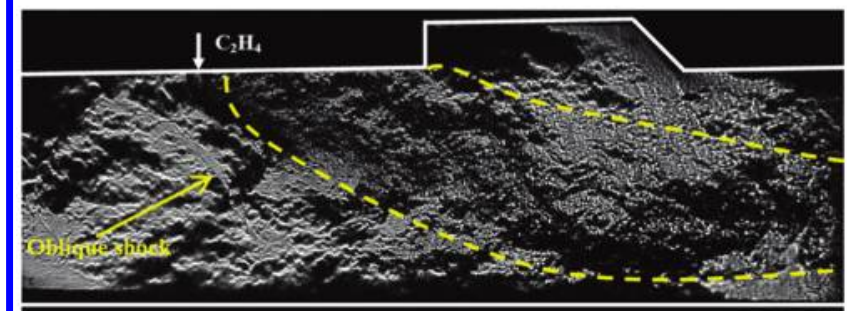

Schlieren image

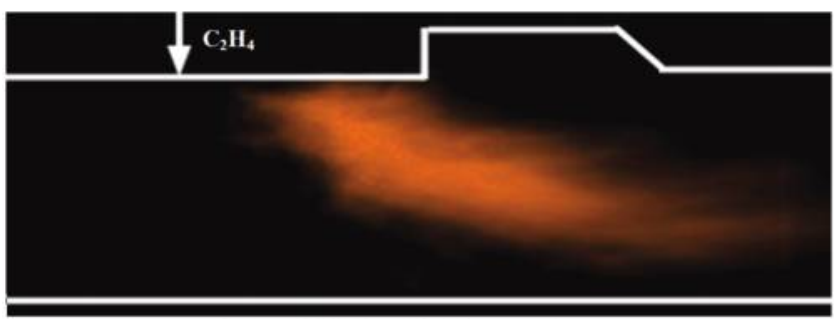

Direct $\mathrm{CH}^{*}$ chemiluminescence image

b) $t=5.640 \mathrm{~s}$

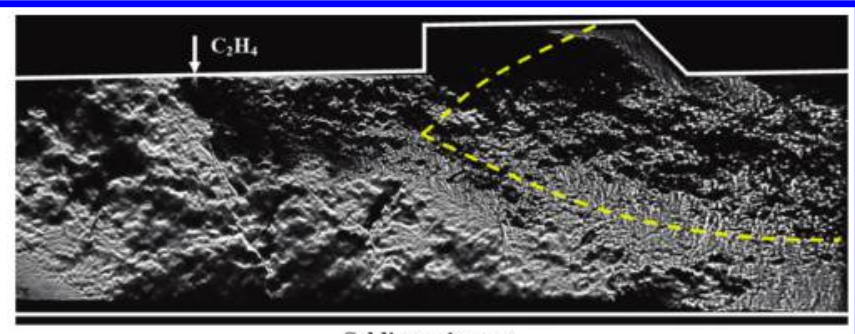

Schlieren image

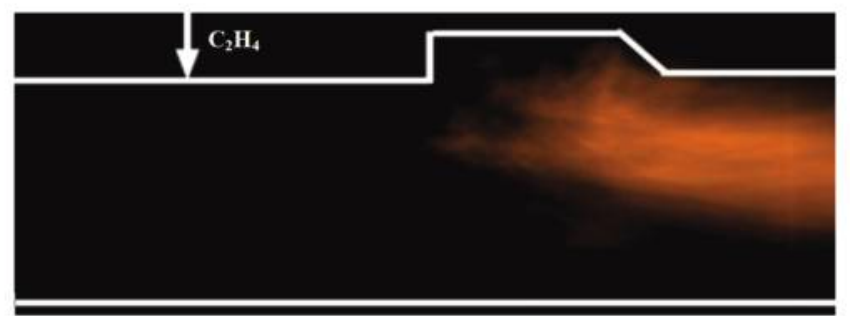

Direct $\mathrm{CH}^{*}$ chemiluminescence image

c) $t=\mathbf{5 . 6 4 5} \mathrm{s}$

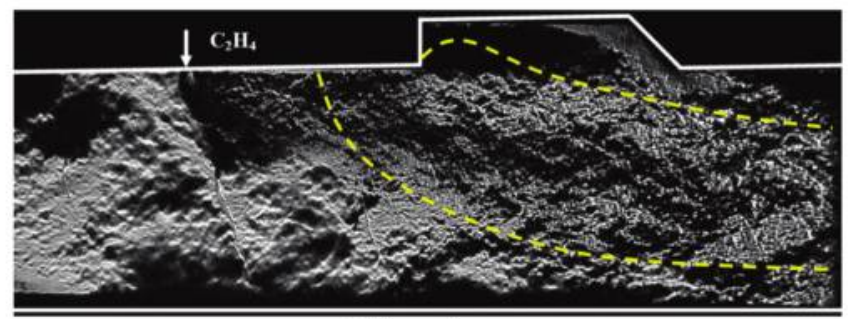

Schlieren image

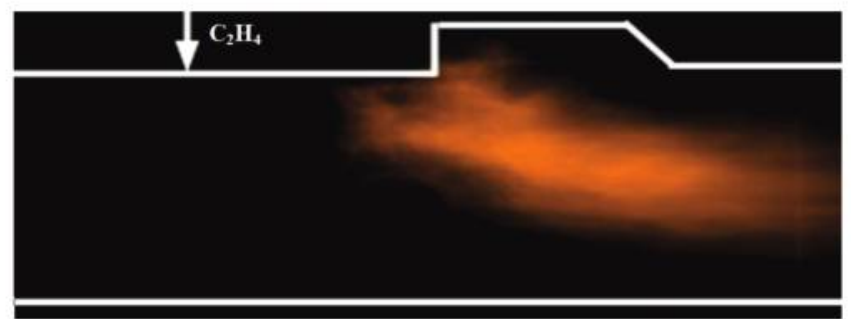

$\mathrm{CH}^{*}$ chemiluminescence image

d) $t=5.650 \mathrm{~s}$

Fig. 11 Schlieren and simultaneous direct $\mathrm{CH}^{*}$ chemiluminescence images for the ethylene combustion at $\varphi=0.376$.

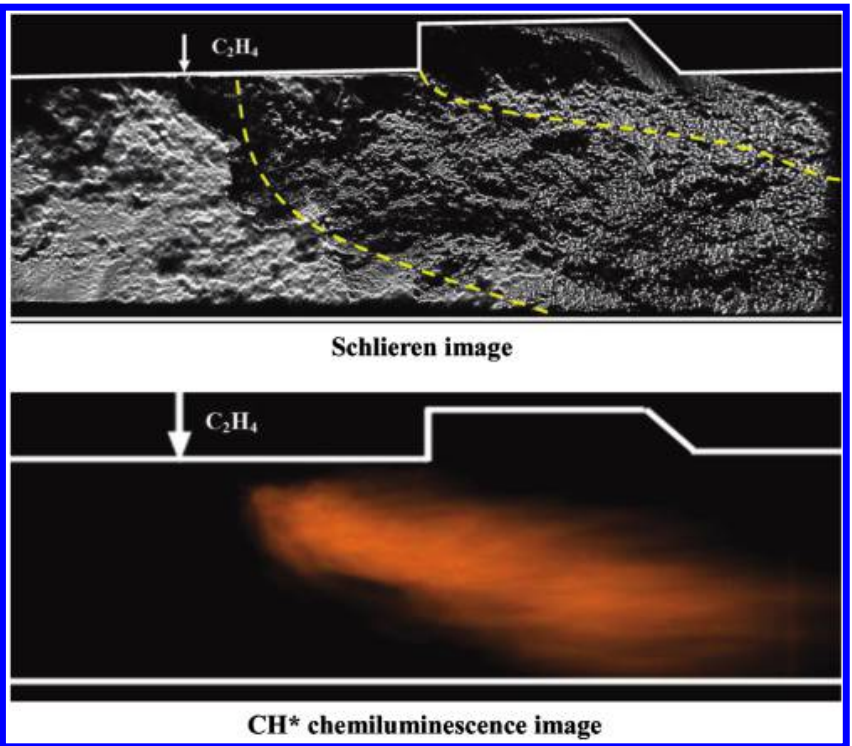

Fig. 12 Schlieren and simultaneous direct $\mathrm{CH}^{*}$ chemiluminescence images for the ethylene combustion at $\varphi=0.411$. the shear layer, and $\mathrm{CH}$ radicals are transited from the cavity into the shear layer. The mixing length of fuel and air before their complete reaction is generally long in this cavity or shear-layer mode. As the equivalence ratio increases, the addition of more heat release chokes the combustor, where the reaction zone is still in the shear layer but partially extends into the mainstream (e.g., the situation in case C). When the heat release is high enough to operate the combustor under ramjet mode (e.g., case E), the shock train is pushed upstream the injector by the high backpressure, and autoignition plays a dominant role in stabilizing the reaction zone in the jet wake. Under a certain heat release condition, the combustor is choked at the injection location, which gives rise to an unsteady flame oscillation between the shear layer and fuel jet wake.

Beside the fuel equivalence ratio, air temperature also highly influences the combustion heat release in dual-mode combustors. Micka and Driscoll [7] have reported that the flame stabilization mode changes as the air stagnation temperature varies.

\section{Conclusions}

In this study, the flame stabilization in a dual-mode combustor was observed through simultaneous detection of the flowfield and the reaction zone. The instantaneous reactive flowfield was clearly visualized using an improved pulsed schlieren system, which can 
effectively suppress the combustion background radiation and freeze the high-speed flowfield effectively with a microsecond scale of exposure time.

Four typical flame stabilization modes in the dual-mode combustor were observed.

1) When no choke occurs, the flame is stabilized inside the cavity or in the shear layer. Schlieren images show that the flow in the reaction zone of the latter shear-layer case is supersonic.

2) As the combustor chokes downstream the fuel injector, the reaction zone is stabilized in the shear layer but starts to extend into the mainstream. The flow in the reaction zone becomes subsonic, and autoignition occurs in the jet wake due to the compression of the shock train. The reaction zone propagates upstream with reduced ignition delay and raised flow residence time behind the shock train.

3) Under certain triggering conditions, when the combustor is choked at the injection location, the reaction zone oscillates between the shear layer and the jet wake. A short-lived aerodynamic throat formed near the injection location due to the blockage of the flow path by the heat addition from the fuel combustion.

4) When the flow speed is reduced to subsonic at the injection location, autoignition plays a dominant role in stabilizing the reaction zone in the jet wake.

The heat release condition in the combustor is proposed to be an important factor that affects the flame stabilization mode. Further studies will be performed to gain better understanding on the flame stabilization modes through the combination of experimental and numerical analysis.

\section{Acknowledgments}

Current research program at the Chinese Academy of Sciences was supported by the National Nature Science Foundation of China under contract number 91016005, 10621202, and the Youth Innovation Fund of LHD. The authors would like to acknowledge G. Yu, J. R. Zhao, L. J. Meng, and X. S. Wei for their helpful discussion and technique support.

\section{References}

-11] Ben-Yakar, A., and Hanson, R. K., "Cavity Flame-Holders for Ignition and Flame Stabilization in Scramjets: An Overview," Journal of Propulsion and Power, Vol. 17, No. 4, 2001, pp. 869-877. doi: $10.2514 / 2.5818$

[2] Gruber, M. R., Baurle, R. A., Mathur, T., and Hsu, K. Y., "Fundamental Studies of Cavity-Based Flameholder Concepts for Supersonic Combustors," Journal of Propulsion and Power, Vol. 17, No. 1, 2001, pp. 146-153. doi: $10.2514 / 2.5720$

[3] Choi, J. Y., Noh, J., Byun, J. R., Lim, J. S., Togai, K., and Yang, V., "Numerical Investigation of Combustion/Shock Train Interactions in a Dual-Mode Scramjet Engine," 17th AIAA International Space Planes and Hypersonic Systems and Technologies Conference, AIAA Paper 2011-2395, April 2011.

[4] Yang, V., Li, J., Choi, J. Y., and Lin, K. C., "Ignition Transient in an Ethylene Fueled Scramjet Engine with Air Throttling Part 1: NonReacting Flow Development and Mixing," 48th AIAA Aerospace Sciences Meeting, AIAA Paper 2010-0409, Jan. 2010.

-[5] Yang, V., Li, J., Choi, J. Y., and Lin, K. C., "Ignition Transient in an Ethylene Fueled Scramjet Engine with Air Throttling Part 2: Ignition and Flame Development," 48th AIAA Aerospace Sciences Meeting, AIAA Paper 2010-0410, Jan. 2010.

-[6] Rasmussen, C. C., Dhanuka, S. K., and Driscoll, J. F., "Visualization of Flameholding Mechanisms in a Supersonic Combustor Using PLIF," Proceedings of the Combustion Institute, Vol. 31, No. 2, 2007, pp. 2505-2512. doi:10.1016/j.proci.2006.08.007

-77] Micka, D. J., and Driscoll, J. F., "Combustion Characteristics of a DualMode Scramjet Combustor with Cavity Flameholder," Proceedings of the Combustion Institute, Vol. 32, No. 2, 2009, pp. 2397-2404. doi:10.1016/j.proci.2008.06.192

-[8] Fotia, M. L., and Driscoll, J. F., "Ram-Scram Transition and Flame/ Shock Train Interactions in a Model Scramjet Experiment," Journal of Propulsion and Power, Vol. 29, No. 1, 2013, pp. 261-273. doi:10.2514/1.B34486
[9] Rasmussen, C. C., and Driscoll, J. F., "Characteristics of CavityStabilized Flames in a Supersonic Flow," Journal of Propulsion and Power, Vol. 21, No. 4, 2005, pp. 765-767. doi:10.2514/1.15095

- [10] Sun, M. B., Wang, Z. G., Liang, J. H., and Hui, G., "Flame Characteristics in Supersonic Combustor with Hydrogen Injection Upstream of Cavity Flameholder," Journal of Propulsion and Power, Vol. 4, No. 24, 2008, pp. 688-696. doi: $10.2514 / 1.34970$

[11] Ben-Yakar, A., "Experimental Investigation of Mixing and Ignition of Transverse Jets in Supersonic Crossflows," Ph.D. Thesis, Stanford Univ., Stanford, CA, 2000.

[12] Micka, D. J., and Driscoll, J. F., "Reaction Zone Imaging in a DualMode Scramjet Combustor Using CH-PLIF," 44th AIAA/ASME/SAE/ ASEE Joint Propulsion Conference and Exhibit, AIAA Paper 20085071, July 2008.

[13] Yu, G., Li, J. G., Zhao, J. R., Qian, D. X., Han, B., and Li, Y., "HydrogenAir Supersonic Combustion Study by Strut Injectors," 34th AIAA/ ASME/SAE/ASEE Joint Propulsion Conference and Exhibit, AIAA Paper 1998-3275, 1998.

[14] Zhang, T. C., Wang, J., Fan, X. J., and Zhang, P., "Combustion of Vaporized Kerosene in Supersonic Model Combustors with Dislocated Dual Cavities," Journal of Propulsion and Power, Vol. 30, No. 5, 2014, pp. $1152-1160$. doi:10.2514/1.B35096

[15] Zhang, T. C., Wang, J., Qi, L., Fan, X. J., and Zhang, P., "Blowout Limits of Cavity-Stabilized Flame of Supercritical Kerosene in Supersonic Combustor," Journal of Propulsion and Power, Vol. 30, No. 5, 2014, pp. $1161-1166$. doi: $10.2514 / 1 . B 35120$

[16] Fan, X. J., Zhong, F. Q., Yu, G., Li, J. G., and Sung, C. J., "Catalytic Cracking and Heat Sink Capacity of Aviation Kerosene Under Supercritical Conditions," Journal of Propulsion and Power, Vol. 25, No. 6, 2009, pp. 1226-1232. doi: $10.2514 / 1.41966$

[17] O'Byrne, S., Doolan, M., Olsen, S. R., and Houwing, A. F. P., "Analysis of Transient Thermal Choking Processes in a Model Scramjet Engine," Journal of Propulsion and Power, Vol. 16, No. 5, 2000, pp. 808-814. doi:10.1007/s001930050159

[18] Laurence, S. J., Karl, S., Schramm, J., and Hannemann, K., "Transient Fluid-Combustion Phenomena in a Model Scramjet," Journal of Fluid Mechanics, Vol. 722, May 2013, pp. 85-120. doi: $10.1017 / \mathrm{jfm} .2013 .56$

[19] Yu, K. H., Wilson, K. J., and Schadow, K. C., "Effect of Flame-Holding Cavities on Supersonic-Combustion Performance," Journal of Propulsion and Power, Vol. 17, No. 6, 2001, pp. 1287-1295. doi: $10.2514 / 2.5877$

[20] Berglund, M., and Fureby, C., "LES of Supersonic Combustion in a Scramjet Engine Model," Proceedings of the Combustion Institute, Vol. 31, No. 2, 2007, pp. 2497-2504 doi:10.1016/j.proci.2006.07.074

[21] Do, H., Im, S. K., Cappelli, M. A., and Mungal, M. G., "Plasma Assisted Flame Ignition of Supersonic Flows over a Flat Wall," Combustion and Flame, Vol. 157, No. 12, 2010, pp. 2298-2305. doi:10.1016/j.combustflame.2010.07.006

[22] Do, H., Cappelli, M. A., and Mungal, M. G., "Plasma Assisted Cavity Flame Ignition in Supersonic Flows," Combustion and Flame, Vol. 157, No. 9, 2010, pp. 1783-1794 doi:10.1016/j.combustflame.2010.03.009

[23] Hsu, K. Y., Carter, C. D., Gruber, M. R., Barhorst, T., and Smith, S., "Experimental Study of Cavity-Strut Combustion in Supersonic Flow," Journal of Propulsion and Power, Vol. 26, No. 6, 2010, pp. 1237-1246. doi: $10.2514 / 1.45767$

[24] Lee, M. P., McMillin, B. K., Palmer, J. L., and Hanson, R. K., "TwoDimensional Imaging of Combustion Phenomena in a Shock Tube Using Planar Laser-Induced Fluorescence," 29th Aerospace Sciences Meeting, AIAA Paper 1991-0460, Jan. 1991. doi: $10.2514 / 6.1991-460$

[25] McIntyre, T. J. P., Houwing, A. F., Palma, P. C. B., Rabbath, P. A., and Fox, J. S., "Optical and Pressure Measurements in Shock Tunnel Testing of a Model Scramjet Combustor," Journal of Propulsion and Power, Vol. 13, No. 3, 1997, pp. 388-394. doi: $10.2514 / 2.5196$

[26] O'Byrne, S., Doolan, M., Olsen, S. R., and Houwing, A. F. P., "Measurement and Imaging of Supersonic Combustion in a Model Scramjet Engine," Shock Waves, Vol. 9, No. 4, 1999, pp. 221-226. doi: $10.2514 / 2.5645$

[27] Anderson, C. D., and Schetz, J. A., "Liquid-Fuel Aeroramp Injector for Scramjets," Journal of Propulsion and Power, Vol. 21, No. 2, 2005, 
pp. $371-374$

doi: $10.2514 / 1.12238$

[28] Kouchi, T., Goyne, C., Rockwell, R., Jr., Reynolds, R., Krauss, R., and McDaniel, J., "Focusing-Schlieren Visualization in Direct-Connect Dual-Mode Scramjet," 18th AIAA/3AF International Space Planes and Hypersonic Systems and Technologies Conference, AIAA Paper 20125834, Sept. 2012. doi: $10.2514 / 6.2012-5834$

[29] Yuan, Y. M., Yang, M., Zhang, T. C., and Fan, X. J., "Visualization of Vaporized Kerosene Combustion in a Supersonic Combustor Using Pulsed Schlieren System," 48th AIAA/ASME/SAE/ASEE Joint Propulsion Conference and Exhibit, AIAA Paper 2012-3848, July-Aug. 2012.

[30] Pan, Y., Tan, J. G., Liang, J. H., Liu, W. D., and Wang, Z. G., "Experimental Investigation of Combustion Mechanisms of KeroseneFueled Scramjet Engines with Double-Cavity Flameholders," Acta Mechanica Sinica, Vol. 27, No. 6, 2011, pp. 891-897. doi:10.1007/s10409-011-0470-8

[31] Kaiser, S. A., Salazer, V. M., and Hoops, A. A., "Schlieren Measurements in the Round Cylinder of an Optically Accessible Internal Combustion Engine," Applied Optics, Vol. 52, No. 14, 2013, pp. 3433-
3443.

doi:10.1364/AO.52.003433

[32] Settles, G. S., Schlieren and Shadowgraph Techniques, 2nd ed., Springer-Verlag, Berlin, 2006, pp. 168-170.

[33] Donbar, J. M., Driscoll, J. F., and Carter, C. D., "Reaction Zone Structure in Turbulent Nonpremixed Jet Flames-From CH-OH PLIF Images," Combustion and Flame, Vol. 122, Nos. 1-2, 2000, pp.1-19. doi:10.1016/S0010-2180(00)00098-5

[34] Micka, D. J., and Driscoll, J. F., "Stratified Jet Flames in a Heated (1364 K) Cross-Flow with Auto-Ignition," 49th AIAA Aerospace Sciences Meeting, AIAA Paper 2011-0321, Jan. 2011.

[35] Micka, D. J., Torrez, S. M., and Driscoll, J. F., "Heat Release Distribution in a Dual-Mode Scramjet Combustor - Measurements and Modeling," 16th AIAA/DLR/DGLR International Space Planes and Hypersonic Systems and Technologies Conference, AIAA Paper 20097362, 2009

J. Seitzman Assocaite Editor 
This article has been cited by:

1. Pradip Xavier, Alexis Vandel, Gilles Godard, Bruno Renou, Frédéric Grisch, Gilles Cabot, Mourad A. Boukhalfa, Michel Cazalens. 2016. Investigation of combustion dynamics in a cavity-based combustor with high-speed laser diagnostics. Experiments in Fluids 57. . [CrossRef]

2. Patton Allison, Kraig Frederickson, Justin W. Kirik, Robert D. Rockwell, Walter R. Lempert, Jeffrey A. SuttonInvestigation of Flame Structure and Combustion Dynamics using $\mathrm{CH} 2 \mathrm{O}$ PLIF and High-Speed $\mathrm{CH}^{*}$ Chemiluminescence in a Premixed Dual-Mode Scramjet Combustor . [Citation] [PDF] [PDF Plus] 